\title{
Karakteristik Kemampuan Siswa SMA Dalam Menyelesaikan Well dan Ill Structured Problems Pada Pembelajaran Fisika
}

\author{
Supeno*, Sri Handono Budi Prastowo, Marlina Puji Rahayu \\ Fakultas Keguruan dan Ilmu Pendidikan, Universitas Jember \\ *Email: supeno.fkip@unej.ac.id
}

Received: 13 Februari 2019;

Accepted: 28 Maret 2020;

Published: 30 Maret 2020

DOI: http://dx.doi.org/10.29303/jpft.v6i1.1053

\begin{abstract}
One effort to improve the quality of learning physics is by developing abilities in problem solving. Problem solving abilities are complex cognitive activities using thought processes. For students, by knowing problem solving abilities, they can do self-reflection and have learning motivation to change for the better. For teachers, knowing students' abilities in problem solving can be used as a guide for designing learning strategies and evaluations that are suitable for improving problem solving skills. For this reason, it is necessary to identify problem solving abilities of high school students. Methods of research data collection using tests and interviews. Tests for measuring problem solving abilities are categorized as ill-structured problems and well-structured problems. The results showed that students were better able to solve well-structured problems than ill-structured problems. The ability of students to solve well-structured problems and ill-structured problems, most of them are included in the category of novice and only a small proportion are categorized as expert. The novice and expert characteristics based on the results of the study is described in detail in the part of discussion.
\end{abstract}

Keywords : Well-Structured Problems; Ill-Structured Problems; Problem Solving.

\section{PENDAHULUAN}

Kurikulum yang diterapkan di Indonesia saat ini adalah Kurikulum 2013. Salah satu kompetensi yang menjadi tuntutan kurikulum 2013 bertujuan untuk memenuhi kebutuhan masa depan dan menyongsong generasi emas Indonesia 2045. Kompetensi tersebut telah ditetapkan dalam Standar Kompetensi Lulusan yang berbasis pada kompetensi abad 21. Kualifikasi kemampuan Kurikulum 2013 meliputi ranah sikap, pengetahuan, dan keterampilan. Berdasarkan kualifikasi kemampuan tersebut, dapat dikatakan bahwa penerapan Kurikulum 2013 pada Sekolah Menengah Atas (SMA) menuntut siswa untuk meningkatkan pengetahuan serta mengembangkan kemampuan berpikir tingkat tinggi pada setiap mata pelajaran. Salah satu upaya untuk mengembangkan kemampuan berpikir tingkat tinggi adalah mengembangkan kemampuan menyelesaikan masalah (Kemdikbud, 2013).
Demikian juga dalam pembelajaran sains, tujuan utamanya adalah mengantarkan siswa pada penguasaan tentang konsep sains dan meningkatkan kemampuan pemecahan masalah (Duschl et al. 2007).

Fisika adalah salah satu cabang Ilmu Pengetahuan Alam (IPA) atau sains yang mempelajari alam beserta fenomenanya. Proses pembelajaran fisika harus mampu mengembangkan kemampuan intelektual. Salah satu indikator dari perilaku intelektual adalah kemampuan dalam menyelesaikan masalah (Moustofa, 2003). Salah satu tujuan pembelajaran fisika dalam Kurikulum 2013 adalah menciptakan manusia yang dapat menyelesaikan masalah yang kompleks dengan cara menerapkan pengetahuan dan pemahaman pada situasi sehari-hari (Kemdikbud, 2013). Konsep fisika yang dipelajari dengan proses menyelesaikan masalah merupakan makna sesungguhnya belajar (Hoellwarth et al., 2005). Salah satu cara yang dapat ditempuh untuk 
meningkatkan mutu pembelajaran fisika adalah dengan mengintensifkan pengembangan kemampuan peserta didik dalam menyelesaikan masalah fisika sebagai pemeriksaan hasil belajar melalui prosesproses sains dengan menggunakan metode ilmiah (Sambada, 2012).

Kemampuan menyelesaikan masalah merupakan aktivitas kognitif kompleks yang melibatkan kemampuan tingkat tinggi, diantaranya visualisasi, asosiasi, abstraksi, manipulasi, penalaran, analisis, sistesis dan generalisasi (Kirkley, 2003). Pengembangan kemampuan menyelesaikan masalah pada siswa menjadi tujuan utama oleh peneliti maupun praktisi dalam pembelajaran sains (Hsu et al., 2004; Jonassen, 2000). Siswa harus memiliki kemampuan menyelesaikan masalah agar mampu menyelesaikan berbagai permasalahan riil dalam kehidupan sehari-hari (Walker \& Lofton, 2003; Chin \& Chia, 2004). Untuk itu, dalam pembelajaran fisika, guru harus merancang pembelajaran yang mengarahkan siswa pada pencapaian kemampuan penyelesaian masalah.

Beberapa peneliti menyarankan penerapan strategi pembelajaran yang sesuai dengan karakteristik siswa (Barak, 2013; Barak and Mesika, 2007; Gillies and Hynes, 2011; Gillies and Khan, 2008; Gog et al., 2011; Hidayah et al., 2019; Salden et al., 2010) serta penggunaan laboratorium virtual (Sutarno et al, 2017; Gunawan et al, 2017) agar pembelajaran dapat mengembangkan kemampuan siswa dalam menyelesaikan masalah. Beberapa peneliti lain merancang scaffolding untuk membantu siswa berkategori novice (Abdani et al., 2018; Ge et al., 2005; Ge \& Land, 2003; Bulu \& Pederson, 2010) agar memiliki kemampuan menyelesaikan masalah yang baik. Dengan banyaknya penelitian yang mengembangkan penggunaan strategi pembelajaran yang sesuai untuk meningkatkan kemampuan menyelesaikan masalah maka perlu adanya identifikasi kemampuan menyelesaikan masalah pada siswa SMA dalam pembelajaran fisika. Kemampuan menyelesaikan masalah pada siswa SMA perlu diketahui agar guru dapat memilih strategi pembelajaran dan memberikan bimbingan yang tepat dalam proses pembelajaran. Kirschner et al. (2006) mengusulkan strategi pembelajaran yang dapat digunakan untuk membantu siswa dalam mengembangkan kemampuan menyelesaikan masalah. Walaupun demikian, guru harus mendapatkan informasi tentang karakteristik siswa agar dapat merancang pembelajaran yang berkualitas untuk memenuhi kebutuhan siswa (Bennett, 2010; Isman, 2011). Dengan mengetahui karakteristik siswa, guru dapat memodifikasi strategi pembelajaran yang tepat untuk mengembangkan kemampuan menyelesaikan masalah (Harper, 2004). Untuk itu perlu diketahui sejak awal bagaimana kemampuan siswa dalam menyelesaikan masalah sehingga strategi pembelajaran yang dirancang guru sesuai dengan karakteristik siswa.

Tujuan dari penelitian ini adalah untuk mendeskripsikan kemampuan menyelesaikan masalah berstruktur jelas (well-structured problems) dan masalah berstruktur tak jelas (ill-structured problems) pada siswa SMA dalam pembelajaran fisika. Well-structured problems memiliki informasi yang cukup dan tersedia strategi penyelesaiannya serta umumnya hanya memiliki satu atau beberapa jawaban yang benar. Sebaliknya, ill-structured problems umumnya memiliki berbagai kemungkinan jawaban yang benar dan umumnya informasi yang disediakan tidak lengkap (Clariana et al., 2013). Illstructured problems umumnya berupa permasalahan yang sering ditemui dalam kehidupan sehari-hari, di mana satu atau beberapa aspek dari permasalahan tidak 
ditentukan dengan baik, tujuannya tidak jelas, dan ada informasi yang tidak cukup untuk menyelesaikannya (Ge \& Land, 2004). Dengan mengetahui kemampuan tersebut maka siswa dapat melakukan instropeksi diri dan memiliki motivasi untuk berubah menjadi lebih baik. Bagi guru, penelitian ini dapat dijadikan referensi dan pertimbangan dalam merancang strategi pembelajaran yang dapat mengajarkan kemampuan menyelesaikan masalah dan sesuai dengan karakteristik siswa.

\section{METODE PENELITIAN}

Penelitian dilakukan dalam lima tahapan, yaitu (1) menentukan daerah dan subyek penelitian, (2) menyusun instrumen penelitian, berupa soal uraian untuk mengukur kemampuan menyelesaikan masalah, (3) melakukan tes kemampuan menyelesaikan masalah, (4) analisis data dan wawancara, dan (5) interpretasi hasil tes dan penarikan kesimpulan.

Penelitian dilakukan di beberapa Sekolah Menengah Atas (SMA) yang ada di kabupaten Jember. Subjek penelitian adalah siswa kelas X IPA sebanyak 164 siswa. Penelitian dilaksanakan pada awal semester gasal tahun 2018/2019.

Intrumen tes yang digunakan dalam penelitian adalah tes kemampuan menyelesaikan masalah berupa soal uraian jenis ill-structured problems dan wellstructured problems. Soal tersebut diadaptasi dari beberapa soal yang ada di buku karya Young and Freedman (2016) dan buku karya Tipler and Mosca (2008). Soal tersebut merupakan soal yang disajikan dalam bentuk masalah tentang dinamika gerak. Soal yang digunakan berupa soal uraian berjumlah 4 soal dengan rincian 2 soal dengan tipe well-structured problems dan 2 soal dengan tipe ill-structured problems. Soal well-structured problems sebanyak 2 butir, yaitu tentang penentuan gaya yang perlukan untuk memindahkan benda menuju ketinggian tertentu, dan tentang penentuan tegangan tali pada sistem yang bergerak. Soal ill-structured problems sebanyak 2 butir, yaitu tentang prinsip fisika untuk pemasangan lampu gantung agar tahan gempa dan prinsip fisika untuk pemasangan sabuk pengaman pada mobil.

Wawancara dilakukan oleh peneliti untuk mengkonfirmasi jawaban dari soal yang telah diberikan siswa. Konfirmasi ini dimaksudkan untuk mengetahui struktur jawaban dan kompleksitas jawaban. Untuk memperlancar dalam perolehan data saat wawancara, peneliti menggunakan pedoman wawancara berupa pertanyaan-pertanyaan yang digunakan untuk mengkonfirmasi jawaban yang diberikan siswa saat tes.

Analisis kemampuan siswa dalam menyelesaikan ill-structured problems dan well-structured problems dilakukan dengan cara menilai kemampuan siswa dengan mengacu pada indikator. Indikator kemampuan menyelesaikan masalah meliputi mengenali masalah, merencanakan strategi, menerapkan strategi, dan mengevaluasi strategi. Penilaian setiap indikator mengacu pada pedoman penskoran. Selanjutnya data dianalisis dengan melakukan perhitungan persentase nilai kemampuan menyelesaikan masalah tiap kategori masalah (ill-structured problems dan well-structured problems) dan tiap indikator penyelesaian masalah. Indikator penyelesaian masalah yang diteliti meliputi mengenali masalah, merencanakan strategi, menerapkan strategi, dan evaluasi (Sujarwanto, 2014). Indikator tersebut merupakan tahapan yang harus dilakukan oleh siswa saat menyelesaikan masalah.

Langkah selanjutnya adalah penyajian data. Data yang telah dianalisis selanjutnya disajikan dalam bentuk tabel. Selanjutnya dilakukan interprestasi data. Interpretasi data dilakukan untuk memaknai serangkaian data 
yang telah disajikan dengan menafsirkan atau menjabarkan data yang telah disajikan. Data-data kemampuan menyelesaikan illstructured problems dan well-structured problems diterjemahkan menjadi serangkaian kata dengan data pendukung berupa hasil wawancara. Adapun tahapan terakhir adalah menarik kesimpulan dari hasil interpretasi kemampuan menyelesaikan ill-structured problems dan well-structured problems pada siswa SMA.

\section{HASIL DAN PEMBAHASAN}

Kemampuan menyelesaikan masalah merupakan kemampuan yang harus dimiliki oleh siswa agar siap menghadapi masalah riil dalam kehidupan sehari-hari. Permasalahan yang diajukan pada siswa dikategorikan ke dalam dua jenis, yaitu well-structured problems dan ill-structured problems. Kemampuan siswa dalam menyelesaikan illstructured problems dan well-structured problems ditinjau berdasarkan tahapan menyelesaikan masalah ditunjukkan pada Tabel 1.

Tabel 1. Kemampuan problem solving tiap indikator

\begin{tabular}{cccccccccc}
\hline & \multicolumn{7}{c}{ Persentase Siswa } \\
\cline { 2 - 9 } $\begin{array}{c}\text { Katego } \\
\text { ri }\end{array}$ & \multicolumn{7}{c}{$\begin{array}{c}\text { Well-Structured } \\
\text { Problems }\end{array}$} & \multicolumn{7}{c}{ Ill-Structured Problems } \\
\cline { 2 - 9 } & A & B & C & D & A & B & C & D \\
\hline $\begin{array}{c}\text { Sangat } \\
\text { Baik }\end{array}$ & $\begin{array}{c}90,2 \\
4\end{array}$ & $\begin{array}{c}79,8 \\
8\end{array}$ & $\begin{array}{c}50,6 \\
1\end{array}$ & $\begin{array}{c}26,8 \\
3\end{array}$ & $\begin{array}{c}22,5 \\
6\end{array}$ & $\begin{array}{c}29,8 \\
8\end{array}$ & 6,10 & $\begin{array}{c}31,1 \\
0\end{array}$ \\
\hline Baik & 7,32 & 4,88 & $\begin{array}{c}24,3 \\
9\end{array}$ & $\begin{array}{c}22,5 \\
6\end{array}$ & $\begin{array}{c}47,5 \\
6\end{array}$ & $\begin{array}{c}21,3 \\
4\end{array}$ & 19,5 & 17,6 \\
8
\end{tabular}

Berdasarkan Tabel 1 terlihat bahwa kemampuan sebagian besar siswa pada tiap indikator menyelesaikan masalah untuk wellstructured problems sangat memuaskan. Hal ini terlihat pada indikator mengenali masalah, dimana sebagian besar siswa menunjukkan kemampuannya. Berdasarkan analisis terhadap jawaban yang diberikan siswa, diketahui bahwa sebagian besar siswa mampu mengidentifikasi masalah berdasarkan konsep dasar, mampu membuat daftar besaran yang diketahui, dan menentukan besaran yang ditanyakan. Demikian juga pada indikator merencanakan strategi, sebagian besar siswa memiliki kemampuan dalam memilih strategi penyelesaian masalah secara tepat. Sebagian besar siswa juga mampu memvisualkan permasalahan, baik dalam bentuk diagram benda bebas maupun sketsa serta menentukan persamaan yang tepat untuk menyelesaikan masalah. Pada indikator menerapkan strategi, sebagian besar siswa mampu menerapkan strategi dengan baik dan hanya sebagian kecil siswa saja yang belum mampu menerapkan strategi dengan baik. Sebagian besar siswa mampu dalam mensubsitusi nilai besaran yang diketahui ke persamaan matematis dan melakukan perhitungan menggunakan persamaan yang telah ditentukan. Sedikit berbeda untuk kemampuan evaluasi, dimana sebagian siswa mampu melakukan evaluasi dan sebagian lainnya masih kurang mampu dalam melakukan evaluasi. Hal ini menunjukkan bahwa hanya sebagian siswa saja yang melakukan pengecekan kembali terhadap proses penyelesaian masalah yang telah dilakukan dan kesesuaiannya dengan konsep fisika.

Tabel 1 juga menyajikan kemampuan siswa dalam menyelesaikan ill-structured problems. Terlihat bahwa kemampuan siswa dalam menyelesaikan ill-structured problems masih kurang memuaskan. Berdasarkan analisis terhadap jawaban yang diberikan siswa, diketahui bahwa sebagian besar siswa kurang mampu menggunakan kondisi yang dinyatakan dalam masalah untuk menentukan konsep fisika yang 
relevan dan mengidentifikasi variabel yang dicari. Sebagian besar siswa juga kurang mampu dalam memvisualisasikan permasalahan dari representasi verbal menjadi representasi visual, membuat daftar variabel yang diketahui dan tidak diketahui, serta mengidentifikasi konsep dasar fisika yang terkait dengan masalah. Siswa kurang mampu dalam merencanakan solusi dengan cara mengubah deskripsi fisika menjadi representasi matematis serta melaksanakan rencana dengan melakukan operasi matematis. Padahal siswa dituntut harus menggabungkan prinsip dan konsep, di samping itu siswa harus menyelesaikan perhitungan dengan benar, runtut, dan lengkap.

Kemampuan siswa dalam mengenali masalah pada well-structured problems lebih baik dibanding ill-structured problems. Menurut wawancara dengan guru, saat menyelesaikan masalah fisika, siswa selalu diajarkan untuk mengenali masalah, yaitu membaca secara cermat dan mengidentifikasi masalah berdasarkan konsep fisika, membuat daftar besaran yang diketahui dan yang tidak diketahui, serta menentukan besaran-besaran fisika yang ditanyakan. Meskipun guru sudah mengajarkan tentang mengenali masalah namun dikarenakan komponen masalah yang ditampilkan tidak lengkap sehingga siswa kebingungan.

Kemampuan siswa dalam merencanakan strategi pada saat menyelesaikan well-structured problems lebih baik daripada pada ill-structured problems. Hal ini dikarenakan penyelesaian ill-structured problems membutuhkan kemampuan lebih kompleks daripada wellstructured problems. Menurut keterangan siswa saat dilakukan wawancara, siswa tidak terbiasa menuliskan strategi yang digunakan sehingga kesulitan dalam merencanakan strategi. Di samping itu, siswa terbiasa menghafalkan formulasi fisika sehingga kesulitan dalam memaknai arti fisis dari formulasi fisika tersebut. Hal ini didukung dengan data hasil wawancara dengan guru yang menyatakan bahwa siswa tidak terbiasa menuliskan strategi yang akan digunakan untuk menyelesaikan masalah. Siswa lebih sering menghafal formulasi matematis dan menghafal apa yang sudah diterima. Siswa juga sering kesulitan ketika ada masalah yang belum pernah mereka temui sebelumya meskipun secara prinsip masalah tersebut indentik.

Kemampuan siswa dalam menerapkan strategi pada saat menyelesaikan wellstructured problems lebih baik daripada saat menyelesaikan ill-structured problems. Berdasarkan data yang diperoleh, persentase jumlah siswa yang mampu merencanakan strategi lebih besar daripada persentase jumlah siswa dalam menerapkan strategi, baik pada ill-structured problems maupun well-structured problems. Hal ini menunjukkan bahwa meskipun siswa mampu merencanakan strategi dengan baik namun belum tentu mampu menerapkan strategi dengan baik. Hal ini sejalan dengan hasil penelitian sebelumnya yang menyatakan bahwa siswa kesulitan menuangkan ide ke dalam solusi yang tepat (Noviatika et al., 2019). Berdasarkan analisis yang dilakukan oleh peneliti bahwa masih ada beberapa siswa yang salah konsep serta masih lemah dalam kemampuan matematisnya. Di samping itu, terdapat beberapa siswa yang tidak biasa menggambarkan diagram benda bebas saat menyelesaikan masalah. Ada beberapa siswa yang mampu menggunakan strategi secara tepat namun mereka tidak menyelesaikan masalah hingga tuntas. Sebagian siswa langsung menggunakan formulasi matematis untuk menyelesaikan masalah yang diberikan. Kondisi ini sejalan dengan hasil penelitian sebelumnya yang menyatakan 
bahwa beberapa siswa cenderung langsung menggunakan formulasi matematis tanpa disertai penggunaan representasi yang sesuai sehingga sulit ditentukan apakah mereka memiliki kemampuan pemecahan masalah fisika yang baik (Supeno et al. 2018)

Kemampuan siswa dalam melakukan evaluasi terhadap proses dan hasil penyelesaian well-structured problems maupun ill structured problems masih kurang memuaskan. Berdasarkan analisis dari peneliti, beberapa siswa tidak melakukan evaluasi. Beberapa siswa yang mampu memilih konsep dengan tepat namun mereka kurang teliti dalam pengerjaannya sehingga hasil akhir yang diperoleh belum benar. Ada beberapa siswa yang melakukan penarikan kesimpulan namun kesimpulan yang didapat tidak sesuai dengan maksud dari permasalahan yang diajukan. Berdasarkan hasil wawancara dengan siswa, mereka mengatakan bahwa tidak terbiasa melakukan evaluasi untuk meninjau ulang apakah proses yang dilakukan saat menyelesaikan masalah sudah tepat. Padahal siswa yang melakukan evaluasi dengan cara meninjau kembali proses penyelesaian masalah akan memiliki kemampuan penyelesaian masalah yang baik (Lee, 2016). Alternatif solusi yang dapat ditawarkan agar siswa terbiasa mengevaluasi proses penyelesaian masalah adalah dengan aktivitas praktikum menggunakan laboratorium virtual (Sutarno et al., 2017; Gunawan et al., 2017) serta aktivitas kolaboratif (Fitriyani et al., 2019).

Masalah yang diajukan kepada siswa dibedakan menjadi dua macam, yaitu wellstructured problems dan ill-structured problems. Secara umum kemampuan siswa dalam menyelesaikan well-structured problems dan ill-structured problems ditunjukkan pada Tabel 2.

Tabel 2. Kemampuan menyelesaikan well dan ill-structured problems.

\begin{tabular}{ccc}
\hline \multirow{2}{*}{ Kategori } & \multicolumn{2}{c}{ Persentase Jumlah Siswa (\%) } \\
\cline { 2 - 3 } & $\begin{array}{c}\text { Well } \text {-structured } \\
\text { problems }\end{array}$ & $\begin{array}{c}\text { Ill-structured } \\
\text { problems }\end{array}$ \\
\hline Sangat Baik & 58,53 & 6,09 \\
\hline Baik & 21,95 & 35,97 \\
\hline Cukup & 17,68 & 29,87 \\
\hline Kurang & 1,82 & 25,60 \\
\hline $\begin{array}{c}\text { Sangat } \\
\text { Kurang }\end{array}$ & 0 & 2,43 \\
\hline
\end{tabular}

Berdasarkan data pada Tabel 2 nampak bahwa kemampuan menyelesaikan well-structured problems lebih didominasi pada kategori sangat baik. Hal ini berbeda dengan data untuk kemampuan menyelesaikan ill-structured problems dimana dominasi berada pada kategori baik, cukup, dan kurang yang berarti bahwa hanya sebagian kecil siswa yang memiliki kemampuan yang baik dalam menyelesaikan ill-structured problems.

Tingkat kemampuan siswa dalam menyelesaikan masalah diklasifikasikan menjadi dua, yaitu kelompok novice dan kelompok expert. Berdasarkan analisis terhadap hasil penyelesaian masalah, diperoleh data bahwa siswa dalam kategori expert mampu menerapkan konsep dan prinsip dengan tepat, dapat menghubungkan objek dan konsep dengan prinsip fisika, dapat merepresentasikan suatu masalah dengan terstruktur, dan dapat melakukan evaluasi proses dan hasil penyelesaian masalah dengan baik. Sedangkan pada kategori novice, siswa kurang mampu menerapkan konsep dan prinsip dengan tepat, kurang mampu menghubungkan objek dan konsep dengan prinsip fisika, kurang mampu merepresentasikan suatu masalah dengan terstruktur, dan tidak melakukan evaluasi proses dan hasil penyelesaian masalah dengan baik. Berdasarkan analisis yang dilakukan oleh peneliti, kelompok novice dapat dikelompokkan ke dalam beberapa tipe sebagaimana ditunjukkan pada Tabel 3.

Tabel 3. Macam-macam kelompok novice

\begin{tabular}{ccc}
\hline \multirow{2}{*}{ Kategori } & \multicolumn{2}{c}{ Persentase Siswa } \\
\cline { 2 - 3 } & $\begin{array}{c}\text { Well-structured } \\
\text { problems }\end{array}$ & $\begin{array}{c}\text { Ill-structured } \\
\text { problems }\end{array}$ \\
\hline C & 24.60 & 27.10 \\
$\mathrm{AC}$ & 6.09 & 3.00
\end{tabular}




\begin{tabular}{|c|c|c|}
\hline $\mathrm{ABC}$ & 29,20 & 18,20 \\
\hline $\mathrm{Z}$ & 2,40 & 12,50 \\
\hline $\mathrm{ABCD}$ & 37,50 (expert) & 39,00 (expert) \\
\hline A & : siswa hanya mampu $\mathrm{m}$ & an konsep dan prinsip \\
\hline B & $\begin{array}{l}\text { siswa hanya mampu } \\
\text { konsep dengan prinsip }\end{array}$ & Ibungkan objek dan \\
\hline $\mathrm{C}$ & $\begin{array}{l}\text { siswa hanya dapat } \\
\text { dengan terstruktur }\end{array}$ & esentasikan masalah \\
\hline $\mathrm{D}$ & : siswa hanya dapat mel & valuasi \\
\hline $\mathrm{AC}$ & : siswa hanya dapat mel & ndikator $\mathrm{A}$ dan $\mathrm{C}$ \\
\hline $\mathrm{ABC}$ & $\begin{array}{l}\text { : siswa hanya dapat melal } \\
\text { C }\end{array}$ & da indikator A, B, dan \\
\hline $\mathrm{ABCD}$ & : siswa dapat melakukan & ndikator \\
\hline
\end{tabular}

Hasil penelitian menunjukkan bahwa sebagian besar siswa termasuk dalam kategori novice dan hanya sebagian kecil yang berkategori expert, baik untuk wellstructured problems maupun ill-structured problems. Siswa dengan kategori expert memiliki beberapa kararteristik, yaitu mampu menerapkan konsep dan prinsip dengan tepat, dapat menghubungkan objek dan konsep dengan prinsip fisika, dapat merepresentasikan masalah dengan lengkap dan benar, dan dapat melakukan evaluasi. Hal ini menunjukkan bahwa siswa dalam kategori expert memiliki keterampilan dan pengetahuan kognitif maupun metakognitif (Yousoof et al., 2006; Matlin, 2002; Glaser, 1999; Sternberg, 2006).

Siswa berkategori novice ada beberapa kelompok kemampuan. Pada kelompok pertama, siswa hanya mampu merepresentasikan masalah. Pada kelompok kedua, siswa hanya mampu merepresentasikan masalah dan memilih konsep dengan tepat. Pada kelompok ketiga, siswa hanya mampu merepresentasikan masalah, memilih konsep dengan tepat, dan menghubungkan objek dan konsep dengan prinsip fisika. Pada kelompok keempat, yaitu siswa yang tidak dapat merepresentasi masalah, tidak dapat memilih konsep fisika yang sesuai dengan masalah, tidak dapat menghubungkan objek dan konsep serta prinsip fisika yang sesuai, dan tidak dapat melakukan evaluasi proses dan hasil. Hal ini sesuai dengan penelitian sebelumnya bahwa pada kelompok novice hanya melihat permukaan masalahnya, gagal dalam menghubungkan objek dengan prinsip fisika dan belum mampu mengetahui keseluruhan unsur yang ada dalam masalah dan kesulitan dalam menghadapi masalah yang kompleks (Byun et al. 2014; Ge \& Land 2004; Xie \& Bradshaw, 2008).

\section{PENUTUP}

Berdasarkan hasil penelitian secara keseluruhan dapat disimpulkan bahwa: (1) kemampuan siswa dalam mengenali masalah, merencanakan strategi, dan menerapkan strategi pada well-structured problems sebagian besar sudah sangat baik sedangkan pada ill-structured problems sebagian besar siswa masih kurang memuaskan; (2) kemampuan siswa dalam melakukan evaluasi baik pada wellstructured problems maupun ill-structured problems masih belum memuaskan; dan (3) saat menyelesaikan well-structured problems maupun ill-structured problems, sebagian besar siswa masih berkategori novice. Berdasarkan hasil dari penelitian ini, peneliti menyarankan agar guru membiasakan siswa untuk menyelesaikan well-structured problems dan ill-structured problems. Guru juga diharapkan menerapkan berbagai strategi pembelajaran inovatif yang diarahkan pada peningkatan kemampuan siswa dalam menyelesaikan masalah, seperti penggunaan model pembelajaran yang tepat, pemberian scaffolding, termasuk penggunaan teknologi untuk pembelajaran. Salah satu teknologi yang dapat diterapkan adalah penggunaan laboratorium virtual.

\section{REFERENSI}

Abdani, R., Rokhmat, J., \& Rahayu, S. (2018). Pengaruh Pendekatan Berpikir Kausalitik Ber-Scaffolding Dengan Pemberian Tugas Pendahuluan 
Terhadap Kemampuan Pemecahan Masalah Siswa SMA. Jurnal Pendidikan Fisika dan Teknologi, 4(2), 213-219.

Barak. (2013). Impacts of Learning Inventive Problem-Solving Principles: Students' Transition from Systematic Searching to Heuristic Problem Solving. Instructional Science, 41(4), 657-679.

Barak, M. \& Mesika, P. (2007). Teaching Methods for Inventive ProblemSolving in Junior High School. Thinking Skills and Creativity, 2(1), 19-29.

Bennett, S. (2010). Investigating Strategies for Using Related Cases to Support Design Problem Solving. Educational Technology Research and Development, 58(4), 459-480.

Bulu, S T. \& Pederson, S. (2010). Scaffolding Middle School Students' Content Knowledge and Ill-Structured Problem Solving in A Problem-Based Hypermedia Learning Environment. Educational Technology Research and Development, 58(5), 507-529.

Byun, H., Lee, J. \& Cerreto, F A. (2014). Relative Effects of Three Questioning Strategies in Ill-Structured, Small Group Problem Solving. Instructional Science, 42(2), 229-250.

Chin, C. \& Chia, L. G. (2004). ProblemBased Learning: Using Students' Questions to Drive Knowledge Construction, Science Education, 88(5), 707-727.

Clariana, R. B., Engelmeann, T, \& Yu, W. (2013). Using Centrality of Concept Maps as A Measure of Problem Space States in Computer-Supported Collaborative Problem Solving. Educational Technology Research and Development, 61(3), 423-442.

Duschl, R. A., Schweingruber, H. A., \& Shouse, A. W. (Eds.). (2007). Taking Science to School: Learning and Teaching Science in Grades K-8.
Washington: National Academies Press.

Fitriyani, R. V., Supeno, \& Maryani, M. (2019). Pengaruh LKS Kolaboratif Pada Model Pembelajaran Berbasis Masalah Terhadap Keterampilan Pemecahan Masalah Fisika Siswa SMA. Berkala Ilmiah Pendidikan Fisika, 7(2), 71-81.

Ge, X. \& Land, S. M. (2003). Scaffolding Students' Problem-Solving Processes in An Ill-Structured Task Using Question Prompts and Peer Interactions. Educational Technology Research and Development, 51(1), 21-38.

Ge, X. \& Land S. M. (2004). A Conceptual Framework for Scaffolding IllStructured Problem-Solving Processes Using Question Prompts and Peer Interactions. Educational Technology Research and Development, 52(2), 522.

Ge, X., Chen, C., \& Davis, K. A. (2005). Scaffolding Novice Instructional Designers' Problem-Solving Processes Using Question Prompts in A Web-Based Learning Environment. Journal of Educational Computing Research, 33: 219-248.

Gillies, R. M. \& Haynes, M. (2011). Increasing Explanatory Behavior, Problem-Solving, And Reasoning Within Classes Using Cooperative Group Work. Instructional Science, 39(3), 349-366.

Gillies, R. \& Khan, A. (2008). The Effects of Teacher Discourse on Students' Discourse, Problem-Solving and Reasoning During Cooperative Learning. International Journal of Educational Research, 47, 323-340.

Glaser, R. (1999). Expert Knowledge and Processes of Thinking. In: McCormick, R, C Paechter (Eds.). Learning and Knowledge. London: Paul Chapman.

Gog, T V., Kester, L., \& Paas, F. (2011). Effects of Worked Examples, 
Example-Problem, And ProblemExample Pairs on Novices' Learning. Contemporary Educational Psychology, 36(3), 212-218.

Gunawan., Harjono, A., Sahidu, H., \& Herayanti, L. (2017). Virtual Laboratory to Improve Students' Problem-Solving Skills on Electricity Concept. Jurnal Pendidikan IPA Indonesia. 6(2), 257-264.

Harper, K A. (2004). Expert-Novice Comparisons to Illuminate Differences in Perceptions of Problem Solutions, AIP Conference Proceedings, 720(1): 129.

Hidayah, N., Sutrio, \& Hikmawati. (2019). Pengaruh Model Conceptual Understanding Procedures Terhadap Penguasaan Konsep dan Kemampuan Pemecahan Masalah Fisika Peserta Didik Kelas X SMAN 1 Gerung. Jurnal Pendidikan Fisika dan Teknologi, 5(1), 182-189.

Hoellwarth, C., M. J. Moelter, \& Knight, R. D. (2005). A Direct Comparison of Conceptual Learning and ProblemSolving Ability in Traditional and Studio Style Classrooms. American Journal of Physics, 73(5), 459-462.

Hsu, L., Brewe, E., Foster, T., \& Harper, K. (2004). Resource letter RPS-1: Research in Problem Solving. American Journal of Physics, 72(9), 1147-1156.

Isman, A. (2011). Instructional Design in Education: New Model. The Turkish Online Journal of Educational Technology, 10(1), 136-142.

Jonassen, D. H. (2000). Toward A Design Theory of Problem Solving. Educational Technology and Research and Development, 48(4), 63-85.

Kemdikbud. (2013). Permendikbud Nomor 65 Tahun 2013 Tentang Standar Isi Pendidikan Dasar dan Menengah Kurikulum 2013. Jakarta.
Kirkley, J. (2003). Principles for Teaching Problem Solving, Technical Paper. Indiana: Plato Learning, Inc.

Kirschner, P. A., Sweller, J., \& Clark, R. (2006). Why Minimal Guidance During Instruction Does Not Work: An Analysis of The Failure of Constructivist, Discovery, ProblemBased, Experiential, And InquiryBased Learning. Educational Psychologist, 41(2), 75-86.

Lee, S-Y. (2016). Students' Use Of "Look Back" Strategies in Multiple Solution Methods. International Journal of Science and Mathematics Education, 14(4), 701-717.

Matlin, M.W. (2002). Cognition. (5th ed.). Fort Worth: Harcourt College Publishers.

Moustofa, K. S. (2003). Too intelligent for job? The Validity of Upper-Limit Cognitive Ability Test Scores in Selection. S.A.M Advanced Management Journal, 68(2), 4-10.

Noviatika, R., Gunawan, \& Rokhmat, J. (2019). Pengaruh Model Pembelajaran Berbasis Masalah Berbantuan Mobile Pocket Book Fisika Terhadap Kemampuan Pemecahan Masalah Peserta Didik. Jurnal Pendidikan Fisika dan Teknologi, 5(2), 240-246.

Salden, R J C M., Aleven, V., Schwonke, R. \& Renki, A. (2010). The Expertise Reversal Effect and Worked Examples in Tutored Problem Solving. Instructional Science, 38(3), 289-307.

Sambada, D. (2012). Peranan Kreativitas Siswa Terhadap Kemampuan Memecahkan Masalah Fisika Dalam Pembelajaran Kontekstual. Jurnal Penelitian Fisika dan Aplikasinya, 2(2), 37-47.

Sternberg, R.J. (2006). Cognitive Psychology. (4th ed.). United Kingdom: Thomson Wadsworth.

Sujarwanto, E., Hidayat, A., \& Wartono. (2014). Kemampuan Pemecahan Masalah Fisika Pada Modeling 
Instruction Pada Siswa SMA Kelas XI, Jurnal Pendidikan IPA Indonesia, $3(1), 65-78$.

Supeno, Subiki, \& Rohma, L. W. (2018). Students' Ability in Solving Physics Problems on Newtons' Law of Motion. Jurnal Ilmiah Pendidikan Fisika Al-BiRuNi, 7(1), 59-70.

Sutarno, Setiawan, A., Suhandi, A., Kaniawati, I., \& Putri D. H. (2017). Keterampilan Pemecahan Masalah Mahasiswa Dalam Pembelajaran Bandul Fisis Menggunakan Model Problem Solving Virtual Laboratory. Jurnal Pendidikan Fisika dan Teknologi, 3(2), 164-172.

Tipler, P. A. \& Mosca, G. (2008). Physics for Scientists and Engineers with Modern Physics; 6th Edition. New York: W. H. Freeman and Company.

Walker, J.T. \& Lofton, S.P. (2003). Effect of A Problem-Based Learning Curriculum on Students' Perceptions of Self-Directed Learning. Issues in Educational Research, 13(2), 71-100.

Young, H. D. \& Freedman, R. A. (2016). Sears and Zemansky's University Physics: with Modern Physics, 14th Edition. San Francisco: Pearson Education, Inc.

Yousoof, M., Sapiyan, M., \& Kamaluddin, K. (2006). Reducing Cognitive Load in Learning Computer Programming. Transactions on Engineering, Computing and Technology, 12, 259262.

Xie, K., \& Bradshaw, A. C. (2008). Using Question Prompts to Support IllStructured Problem Solving in Online Peer Collaborations. International Journal of Technology in Teaching and Learning, 4(2), 148-165. 